\title{
Some important considerations to support innovation in public health systems
}

\author{
Dinesh K Arya* \\ ACT Health Directorate, Australia
}

\begin{abstract}
Innovation in healthcare is a much-desired goal, however, unless the culture and environment are right and leaders proactively plan for innovation, not a lot changes. Both scientific and lay literature contains useful commentary on Innovation. It is useful to consider facilitators and barriers for innovation within healthcare systems, especially public health systems.

The public healthcare system has some unique characteristics that can sometimes impede innovation. It is important to understand these complexities to be able to implement innovative solutions. Some strategies to implement innovation within the public health system are identified.
\end{abstract}

\section{Introduction}

When people encounter barriers they have to overcome, they innovate. Indeed, there are wonderful examples of innovation in healthcare in diagnosis, treatment, equipment and processes and the healthcare sector has certainly benefited from many technological advanced occurring in non-health industries. There have been innovations in digitalisation of health information and in funding arrangements. Within public health services, public policy innovations have also been influential and have informed health reforms and internal business arrangements. All of the above has resulted in considerable improvement including in life expectancy and quality of life [1].

\section{Do we improve or innovate?}

Health services have a long history of ensuring services and service delivery is improving continuously. The evidence of the extent to which errors and omissions are prevalent in the delivery of healthcare has raised awareness of the need to ensure effort goes into minimizing them [2]. Indeed, continuous quality improvement strategies and methods are commonly used in all health services to ensure incremental improvements do occur.

However, innovation maybe something different. It is important that organisations continuously improve and adapt, but it is equally important that there is an investment in healthcare innovation. Both together tend to improve performance, allow the organization to gain competitive advantage, create value and bring about transformational change [3-7].

As compared to the continuous incremental improvement, an appropriate innovation strategy can encourage new ideas, processes, products or procedures that are designed to bring about the significant benefit $[8,9]$. In public sector context, innovation is defined by the Commonwealth Government's Better Practice Guide on Innovations in the Public Sector as the 'creation and implementation of new processes, products, services and methods of delivery which result in significant improvements in the efficiency, effectiveness or quality of outcomes' [10].

\section{Why innovate?}

Over our lifetime there is no doubt that innovations have allowed us to make exponential gains. The nature of innovation has also changed. Whereas supply chain innovations was the focus in the industrial age, as we have progressed to the age of social media and information availability, demand-side innovation have been essential to meet changing customer needs [11].

The innovation goal for an organization or system may be to achieve a competitive advantage, increase productivity, become more efficient or as is the case in the public sector environment (e.g. healthcare) to get better value for the taxpayer. Innovation can certainly be an enabler $[12,13]$. Aside from setting a goal, to innovate firstly there has to be a desire and need to do something new and different. Secondly, the innovator must have the necessary technical expertise to be able to generate the idea and have the knowledge base to use the necessary tools and methods to manage its implementation. Thirdly, the environment has to be created to ensure the sustainability of that innovation.

As far as public health care systems are concerned, there are complex health policy issues that have continued to require innovative solutions. For example, there is no doubt that innovation in models of care and care delivery system are needed to address rapidly changing demographics, increasing cost of new treatments, deal with lifestylerelated health problems e.g. smoking, obesity, alcoholism, etc. Despite changes to the policy, funding and service arrangements waiting lists remain long and the rate of errors and omissions continues to be high [14-16]. The proportion of budget devoted to public health care continues to grow [17].

${ }^{*}$ Correspondence to: Dinesh K Arya, Master Black Belt Lean Six Sigma, Chief Medical Officer, ACT Health Directorate, 4 Bowes Street, Phillip ACT 2606, GPO Box 825 Canberra ACT 2601, Australia, Tel: (02) 51249637, E-mail: Dinesh.Arya@ACT.gov.au

Received: June 08, 2020; Accepted: June 26, 2020; Published: June 29, 2020 
However, the public health system is also faced with numerous challenges and the public health system ship seems to take an awfully long time to innovate. Despite innovations occurring in other sectors, the health sector appears to struggle to learn. Whereas other industries are able to transform their business systems and processes to survive changing market environment, the public health care system appears to take time to adapt and change. Concerns remain about the need for innovation to achieve system integration, manage inefficiencies and waste and redesign care delivery systems to achieve patient or consumer-centred care [18-20].

\section{Public healthcare system complexities have to be managed to allow innovation}

In public health care systems there is neither a lack of need or talent to innovate. However, a prerequisite for implementing and sustaining innovation has to be the engagement of those who are likely to be affected by innovation [21]. This is where complexities begin. In addition to recipients and providers of healthcare, influential stakeholders within the public health care system include administrators, regulators, policymakers, pressure and lobby groups - each with their own priorities and demands. Bringing about a system-wide behavioural change to support innovation across a diverse group of stakeholders is complex [22-24]. Healthcare providers also have their own personal and professional needs [25]. In addition, as far as the public healthcare system is concerned, the influence of politics remains significant. Each health reform is rolled out with sincere intentions to find an innovative solution, however, political considerations can affect and compromise translation of that intent into reality [26].

Healthcare consumers and carers who are often recipients of individualized care, collectively are always keen to ensure that their rights as recipients of care are respected and there are appropriate protections in place to ensure consistency in how care is provided.

When considering system-wide innovation across the public healthcare system, it is understandable that laws and regulations have to ensure that change in risks to do with death, disability and discomfort are managed and processes and systems are appropriately assessed before a new process or intervention is introduced. This can sometimes make the introduction of innovation slow [27].

Public healthcare systems also have to be risk-averse to ensure there is stability and minimum variability. This is to ensure that recipients of healthcare continue to receive benefits they have been promised. Bureaucratic control and limiting policies are necessary to ensure the element of unpredictability can be minimized and operations are smooth. Therefore, any proposal for change must consider legislative and implementation risks, unintended consequences and unanticipated behavioural responses, potential legal challenges, reputational risks, complexity of ministerial, government as well as broader political and community reactions [10].

This can sometimes be in complete contrast to the orientation that an innovative organization must take. Innovation brings novelty and change. It also requires experimentation and if necessary, improvisation. Innovation tends to disturb the equilibrium and can be disruptive. There is potential for inconsistency and consistency can certainly be compromised until the new innovative system and process has been established and made sustainable.

\section{Key ingredients for innovation}

Influence of leaders in preparing an organisation's environment to ensure a culture of innovation has to be key to bringing about sustainable new systems and processes [28]. Leaders, the environment they create and the culture that then develops are most influential in affecting the behaviour of others, promote creativity and establish practices that allow innovation to occur [6,29-33].

Innovation is not just about generating new ideas, but about ensuring that innovation occurs and is sustained. New and innovative ideas have to be nurtured, supports put in place for these ideas to evolve and implementation managed systematically. Unless there is a clear strategy, necessary systems, processes and policies to support innovations, and resources are invested appropriately, innovations are difficult to sustain [34].

For innovation to be permitted, the culture of the organisation has to change to one that allows it to become flexible and agile and one that supports and accommodates new ideas. Investment in ensuring skills to support innovation is needed and resources have to be allocated to find innovative solutions to address emerging needs and opportunities. A culture that encourages, recognises and rewards new ideas and creativity creates the right appetite for innovation to occur.

Innovation also has to be strategised, planned and all stages of innovation from the generation of ideas, implementation, evaluation and making innovation sustainable have to be managed. Building capability to support innovation with training, investment in equipment, information systems and other infrastructure supports is often necessary.

\section{How to become an innovative organization?}

The right leadership, environment and culture are essential to set an appetite for the organization to be prepared to be bold, experimentative and be innovative. This then attracts the right people with the necessary technical expertise and exposure to innovative practices from inside and outside the organization to collaborate. A framework for innovation can then evolve.

Leaders must set the appetite for innovation, be receptive to new ideas and create an environment for these ideas to be tested. The environment and the culture have to be right for innovators to feel that they have permission to innovate and to be bold to test and experiment. Such an environment provides protection to the risk-takers. The organisation is primed to take calculated risks and develops an appetite for variability that may be produced in the process on innovating [35].

When it comes to the public healthcare system, obviously, its responsibility also is to ensure healthcare delivered is consistent and high quality. For a public health system, it is also important to be explicit and transparent about boundaries within which innovation would be allowed to occur.

\section{Conclusions}

For innovation to occur the right leadership, environment and culture are a pre-requisite. This then allows an opportunity to be created that innovators can grasp. There has to be a clear reason for innovation. Innovations occur when there is an issue that needs to be resolved. At times this reason is competition. At other time it may be an opportunity or a crisis - either financial, socio-political, cultural or clinical.

Implementing innovation within public health systems can be challenging. In addition to multiple influential stakeholders, the public health system has to ensure consistency in the quality and access to healthcare. The fact that potential risks of innovation have to be 
proactively managed, can slow the process. Sometimes it can even interfere with the desire or ability of innovators to proceed. This could also be the reason why public health systems have often struggled to take advantage of technological advancements that are easily available and accessible in other sectors.

\section{References}

1. Varkey P, Horne A, Bennet KE (2008) Innovation in Health Care: A Primer. Am J Med Qual 23: 382-388. [Crossref]

2. Weingart SN, Wilson RM, Gibberd RW, Harrison B (2000) Epidemiology of medical error. West J Med 172: 390-393. [Crossref]

3. Zaltman G, Duncan R, Holbek J (1973) Innovation and organizations. New York, NY: Wiley.

4. Woodman RW, Sawyer JE, Griffin RW (1993) Toward a Theory of Organizational Creativity. Academy of Management Review 18: 293-321.

5. Amabile TM (1983) The Social Psychology of Creativity. New York: Springer-Verlag.

6. Amabile TM, Conti R, Coon H, Lazenby J, Herron M (1996) Assessing the Work Environment for Creativity. Academy of Management Journal 39: 1154-1184.

7. Amabile TM (1998) How to Kill Creativity. Harvard Business Review 76: 77-87.

8. Lansisalmi H, Kivimaki M, Aalto P, Ruoranen R (2006) Innovation in Healthcare: A Systematic Review of Recent Research. Nurs Sci Q 19: 66-72. [Crossref]

9. West MA (1990) The Social Psychology of Innovation in Groups. In: West MA FJ, editor. Innovation and Creativity at Work: Psychological and Organizational Strategies. Chichester, UK: Wiley: 309-334

10. Commonwealth of Australia (2009) Innovations in the Public Sector: Enabling Better Performance, Driving New Directions. Better Practice Guide. In: Australia Co, editor. Canberra.

11. Davenport TH, Leibold M, Voelpel S (2006) Strategic Management in the Innovation Economy. Erlangen: Publicis Corporate Publishing and Wiley-VCH Verlag GmBH.

12. Sumii K (1986) Innovation Management. Tokyo: Japan Economics Newspaper Press; 1986.

13. Fagerberg J, Mowery DC, Nelson RR (2005) Innovation and Competitiveness. Oxford: Oxford University Press.

14. McGlynn EA, Asch SM, Adams J, Keesey J, Hicks J, et al. (2003) The Quality of Health Care Delivered to Adults in the United States. $N$ Engl J Med 348: 2635-2645. [Crossref]

15. Agency for Health care Quality and Research (2008) National health Care Quality Report. Rockville, MD.

16. Elixhauser A, Owens P (2007) Adverse Drug Events in U.S. Hospitals, 2004: Statistical Brief \#29. Agency for Health care Quality and Research. [Crossref]
17. AIHW (2010) Australia's health 2010. Canberra: AIHW.

18. Berwick DM (2003) Disseminating Innovations in Health Care. JAMA 289: 1969-1975. [Crossref]

19. Herzlinger RE (2006) Why innovation in health care is so hard. Harv Bus Rev 84: 2-10. [Crossref]

20. Plsek PE (2003) Complexity and the adoption of innovation in health care

21. Heinelt H, Smith R (2003) Sustainability, innovation and participatory governance: A cross national study of the EU eco-management and audit scheme. Ashgate: Aldershot.

22. Greco P, Eisenberg JM (1993) Changing Physicians' Practices. N Engl J Med 329 1271-1273. [Crossref]

23. Shortell SM, Zazzali JI, Burns LR, Alexander JA, Gillies RR, et al. (2001) Implementing Evidence-Based Medicine: the role of market pressures, compensation incentives, and culture in physician organizations. Med Care 39: I62- I78. [Crossref]

24. Shortell SM, Bennett CL, Byck GR (1998) Assessing the Impact of Continuous Quality Improvement on Clinical Practice: What it Will Take to Accelerate Progress. Milbank Q 76: 593-624. [Crossref]

25. Huntington J, Gilliam S, Rosen R (2000) Organizational Development for Clinical Governance. $B M J$ 16: 679-682. [Crossref]

26. Arya DK (2011) Time to salvage National Health and Hospital Reform: at least some of it! Asia Pacific Journal of Health Management 6: 19-22.

27. Faulkner A, Kent J (2001) Innovation and Regulation in Human Implant Technologies: Developing Comparative Approaches. Soc Sci Med 53: 895-913. [Crossref]

28. Cummings LL, O'Connell MJ (1978) Organizational Innovation. Journal of Business Research 6: 33-50.

29. Oldham GR, Cummings A (1996) Employee Creativity: Personal and Contextual Factors at Work. Academy of Management Journal 39: 607-634.

30. Tierney P, Farmer SM, Graen GB (1999) An Examination of Leadership and Employee Creativity: The Relevance of Traits and Relationships. Personnel Psychology 52: 591562

31. Shin SJ, Zhou J (2003) Transformational Leadership, Conservation and Creativity: Evidence from Korea. Academy of Management Journal 46: 703-714.

32. Amabile TM, Schatzel EA, Moneta GB, Kramer SJ (2004) Leader behaviors and the work environment for creativity: Perceived leader support. The Leadership Quarterly 15: 5-32.

33. Scott SG, Bruce RA (1994) Determinants of Innovative Behavior: A Path Model of Individual Innovation in the Workplace. Academy of Management Journal 37: 580-607.

34. Egger WD, Singh SK (2009) The Public Innovator's Playbook: Nurturing bold ideas in government. Deloitte Research.

35. Morris L (2007) Creating the innovation culture. An InnovationLabs White Paper: Innovation Labs.

Copyright: (C2020 Arya DK. This is an open-access article distributed under the terms of the Creative Commons Attribution License, which permits unrestricted use, distribution, and reproduction in any medium, provided the original author and source are credited. 